\title{
Assessing an artificial wetland in Putrajaya, Malaysia, as an alternate habitat for waterbirds
}

\begin{abstract}
Detailed information on bird populations and wetland habitats is highly important for future conservation and management activities. More than $50 \%$ of natural wetland habitats have been lost or degraded due to human intervention, which has negatively affected wetlanddependent bird populations. In this study, the density, diversity and feeding guilds of various bird species in an artificial wetland habitat were examined using a distance sampling point count technique. A total of 20,010 individuals of 102 species representing 40 families were detected from March 2009 to June 2010. In all, 64 species were counted with $72.5 \%$ of 14,520 individuals residents, 22 species were counted with $26.4 \%$ of 5,290 individuals resident-migrants, 13 species were counted with $1.0 \%$ of 196 individuals migrants and three species were counted with $0.1 \%$ of four individuals counted vagrants. Resident birds were present at the highest density and vagrants at the lowest. The most dominant migrant, resident and resident-migrant species were the Oriental Reed Warbler (Acrocephalus orientalis) (0.37 \pm 0.10 birds ha-1), Rock Pigeon ( Columba livia) $(3.91+0.97$ birds ha-1) and Purple Heron (Ardea purpurea) $(1.55 \pm 0.93$ birds ha-1), respectively. The community structure of resident birds was the most diverse and rich compared to migrants, resident-migrants and vagrants. Frugivore/insectivore $(1.04 \pm 0.20$ birds ha-1) was the most dominant feeding guild for migrants, nectarivore/insectivore $(0.64 \pm 0.04$ birds ha- 1$)$ for residents and omnivore $(0.28 \pm$ 0.03 birds ha-1) for resident-migrants. The findings of this research indicate that artificial wetlands can provide an alternative habitat for the foraging and breeding activities of different bird assemblages.
\end{abstract}

Keyword: Artificial wetland; Avian community structure; Density; Diversity; Feeding guilds; Malaysia 